authors are obliged to explain all of our data and not just those bits which confirm our prejudices. Thus, while British psychiatrists seemed to expect more violence from Afro-Caribbean 'cases'-a view implying inferiority - they also saw the illness as likely to be of short duration requiring less medication-a view which is more difficult to classify along this dimension.

The notion of race-thinking introduced by sociologists who study this area is not a Bowdlerisation of racism but a variant of it, potentially more harmful since it is subtle and insidious. The generalisations that, for example, the Welsh are good at rugby and singing and the Jews have a flair for business, do not in themselves imply inferiority, but betray a willingness to describe people on the basis of supposed biological characteristics. People who hold these views can delude themselves that they are not being racist, unlike those who say the Welsh are stupid and the Jews avaricious. There is nothing comfortable about race-thinking since it tends to afflict most of us, including those eager to proclaim their liberal credentials. As Husband (1982) observed wryly: "The essential part of race-thinking is the common sense belief that 'race' is a self-evidently neutral fact, not to be confused with racism which is a special condition of a few disturbed bigots who abuse reality with their prejudice".

Institute of Psychiatry

De Crespigny Park

Denmark Hill

London SE5 8AF

Reference
HuSBand, C. (1982) 'Race' in Britain: Continuity and Change.
London: Hutchison.

\section{The GHQ and the HAD}

SIR: The study by Lewis \& Wessely (Journal, December 1990, 157, 860-864) provides example of the misuse of the Hospital Anxiety and Depression (HAD) scale. As they point out, there is no provision of score values for the sum of the two subscales. This is because the HAD was produced in order to distinguish between the constructs of depression and anxiety and not to provide an alternative to the General Health Questionnaire (GHQ) as a screening test for the presence of a 'global' psychiatric disorder. A major problem in psychiatric research is the nebulous nature of the constructs that psychiatrists use. It is surely time to stop presenting studies in such ill-defined terms.
May I take the opportunity to provide information about the obtainability of the HAD scale. Until recently it was made available, free of charge to applicants from the UK and Republic of Ireland, by the Medical Liaison Service of Upjohn. Upjohn regret that they have been unable to continue this service. Copies of the HAD with in-built scoring device and charts for recording scores have now been printed by the Leeds University Press and are available on application to me. A small charge is now necessary to cover costs and this information is also available.

\section{Clinical Sciences Building}

R. P. SNAITH

St James's University Hospital

Leeds LS9 $7 T E$

\section{Ethnic minorities and the psychiatric system}

SIR: Fahy \& Dunn (Journal, December 1990, 157, 933) mistake my point (Journal, September 1990, 157, 451-452). Besides pointing out their mistakes of citation on the question of treatment, I was not advocating 'anthropological' studies as the proper alternative to descriptive quantitative research. My case vignette study which I cited (the paper on which is available to them) was as purely an empirical and statistical study as they could wish for.

The problem is that their own quantitative study did not support the conclusions which they claimed: that racial bias could not be attributed to psychiatrists. Hence my comment "not unuseful"interesting data but faulty conclusions drawn from it. (A claim to be scientific is no guarantee that those making this claim are indeed so.) I am glad they now agree to a distinction between overt racism and other forms of racism: this was not apparent in their paper. Since my letter we have of course the paper by Lewis et al (Journal, 1990, 157, 410-415) which demonstrates that psychiatrists do indeed make conscious associations between ethnicity and criminality.

Drs Fahy \& Dunn now compound their technically incorrect citation with an error of interpretation: the position they are currently attributing to me in my original paper on the Mental Health Act (Littlewood, 1986) was one (concerning the police) of five general possibilities I listed there for useful consideration, and indeed the one which if it was to be taken as a general conclusion I myself called 'naive'. Not only that, but they then use this interpretation against my rather different criticism of their claim to demonstrate an association between the psychiatrists' diagnosis and treatment, rather than between ethnicity and treatment. They still have two different papers, two different arguments, mixed up. 